\title{
Eradication of Acinetobacter baumannii Planktonic and Biofilm Cells Through Erythrosine-Mediated Photodynamic Inactivation Augmented by Acetic Acid and Chitosan
}

\author{
Zahra Fekrirad $^{1} \cdot$ Esmaeil Darabpour $^{2} \cdot$ Nasim Kashef $^{1}$ \\ Received: 22 September 2020 / Accepted: 10 January 2021 / Published online: 29 January 2021 \\ (c) The Author(s), under exclusive licence to Springer Science+Business Media, LLC part of Springer Nature 2021
}

\begin{abstract}
Photodynamic inactivation (PDI) is an attractive treatment modality for multidrug-resistant bacterial infections. The effectiveness of photosensitization by anionic photosensitizers such as erythrosine B can be further enhanced by the addition of biological or chemical molecules. This study aimed to investigate of the enhancement effect of acetic acid and chitosan on erythrosine-mediated PDI of Acinetobacter baumannii in planktonic and biofilm forms. The planktonic cell growth of three A. baumannii strains was subjected to PDI by using erythrosine B $(50 \mu \mathrm{M})$ in $0.01 \%$ acetic acid and green laser light $(530 \mathrm{~nm})$ at fluence of $40 \mathrm{~J} / \mathrm{cm}^{2}$. The phototoxic effect of erythrosine B $(100 \mu \mathrm{M})$ in combination with chitosan $(12.5 \mathrm{mg} / \mathrm{ml})$ (in a solution of acetic acid) at fluence of $80 \mathrm{~J} / \mathrm{cm} 2$ on biofilms was also evaluated. Finally, the cytotoxicity and phototoxicity of the mentioned mixture were assessed on human fibroblasts. Planktonic cells of all three studied A. baumannii strains were almost eradicated by erythrosine B-mediated PDI in the presence of acetic acid. Also, PDI combined with chitosan resulted in a marked decrease in the number of viable biofilm cells ( $\left.>3 \log _{10} \mathrm{CFU}\right)$. At the same experimental conditions, only $15 \%$ of the fibroblasts were photoinactivated. The results showed that PDI by using erythrosine B in acetic acid is very effective against $A$. baumannii planktonic cells and could eliminate them significantly. Also, chitosan enhanced the anti-biofilm efficacy of erythrosine B-mediated PDI against A. baumannii, suggesting that combination therapy may be useful in targeting biofilms.
\end{abstract}

\section{Introduction}

Acinetobacter baumannii, the most important member of Acinetobacter species, is recognized as causing a broad range of severe hospital-acquired infections. The infections including skin and soft tissue infections, catheter-associated urinary tract infections, bloodstream infections, and ventilator-associated pneumonia [1]. Due to exceedingly increased resistance to disinfectants and major antimicrobials, $A$. baumanni evolved as a global threat in the health-care setting. Several strains are highly resistant to most clinically available antibiotics such as carbapenems and aminoglycosides. Current antimicrobials for treatments of carbapenem-resistant or pan drug-resistant A. baumannii are far from perfect

Esmaeil Darabpour

ismal_dar@yahoo.com; e.darabpour@scu.ac.ir

1 Department of Microbiology, School of Biology, College of Science, University of Tehran, Tehran, Iran

2 Department of Biology, Faculty of Science, Shahid Chamran University of Ahvaz, Ahvaz, Iran therapeutic options [2]. The ability of A. baumannii to form robust biofilms on most abiotic surfaces such as health-careassociated equipment, on occlusive dressings and in the wound, has also created challenges in the health treatment [3]. So, there is an urgent need for alternative drugs and/ or therapies that are capable of inactivating A. baumannii.

Photodynamic inactivation (PDI) offers a promising approach to combat antibiotic resistance. PDI causes a rapid killing of microbial cells (in seconds) and has not produced resistance in bacteria so far. Besides, it could efficiently kill biofilm-grown cells both in vitro and in vivo [4]. PDI utilizes the combination of a non-toxic dye known as photosensitizer (PS) and visible light to produce cytotoxic reactive oxygen species (ROS) that can damage cellular components such as DNA, membrane lipids and proteins, ultimately leading to cell death. To achieve an efficient PDI, photosensitizer must bind to or penetrate the bacterial cell [5].

Erythrosine B (EB), an FDA-approved food dye, is known as a photosensitizer which belongs to the class of anionic xanthene dyes. The efficacy of erythrosine has been confirmed in the lethal photosensitization of pathogenic microorganisms [6]. 
However, it is known that a photosensitizer molecule that bears a net anionic charge cannot effectively exert its PDI effect against gram-negative bacteria due to their outer membrane $(\mathrm{OM})$ barrier that prevents the uptake of anionic compounds [7]. Also, penetration of anionic photosensitizers into the biofilm can be restricted by negatively charged extracellular polysaccharide (EPS), which surround and protect cells.

The effectiveness of photosensitization by anionic PS can be further enhanced by the addition of biological or chemical molecules, which alter the molecular charge and structure of photosensitizer or modify the native consistence of the OM / EPS [8, 9]. Chitosan (Ch) and acetic acid (AA) may have the potential to enhance the efficacy of PDI using erythrosine. Acetic acid, an organic chemical compound, can modify the molecular charge of some photosensitizers under acidic condition that subsequently affect their activity during PDI [10]. Chitosan is a natural polycationic antimicrobial biopolymer known to be able to destabilize the biofilm architecture [11, 12].

To the best of our knowledge, there is no report in the literature on the erythrosine-mediated PDI of A. baumannii. The aim of this study was to investigate the effect of PDI mediated by erythrosine on planktonic (in the presence of acetic acid) and biofilm (in the presence of acetic acid and chitosan) forms of A. baumannii.

\section{Material and Methods}

\section{Strains and Culture Conditions}

A. baumannii ATCC BAA 747 was obtained from Persian Type Culture Collection (PTCC). Two clinical isolates of A. baumannii (AB1 and $\mathrm{AB} 2$ ) recovered from burn wounds (Accidents and burn center of Tehran, Iran) were also used. Both clinical isolates displayed resistance to the following antibiotics: imipenem $(10 \mathrm{mg})$, ciprofloxacin $(5 \mathrm{mg})$, gentamicin $(10 \mathrm{mg})$, and azithromycin $(15 \mathrm{mg})$. All of the synthetic antibiotic disks were produced by Padtan Teb Company (Iran). All strains were maintained in Luria-Bertani (LB) broth at $37^{\circ} \mathrm{C}$.

\section{Photosensitizer and Light Source}

Erythrosine B (Sigma, USA) was used as photosensitizing agent. A $1 \mathrm{mM}$ stock solution of EB was prepared in injectable distilled water and stored at $4{ }^{\circ} \mathrm{C}$ in the dark no longer than 2 weeks before use. Stock solution was filtrated through a $0.2 \mu \mathrm{m}$ polycarbonate membrane and further diluted in injectable distilled water to achieve the desired concentration. The light source used in this study was a $530 \mathrm{~nm}$ diode laser with a maximum output power of $45 \mathrm{~mW}$.

\section{Biofilm Formation Assay}

Biofilm formation ( $24 \mathrm{~h}$ ) was quantified by crystal violet assay, according to our previous studies [13]. A low cutoff (ODc) is defined as $3 \times \mathrm{SD}$ above the mean OD of control wells (uninoculated wells) and bacterial strains were classified into three categories: strong biofilm producer $(4 \times \mathrm{ODc}<\mathrm{OD})$, moderate biofilm producer $(2 \times \mathrm{ODc}<\mathrm{OD} \leq 4 \times \mathrm{ODc})$, and weak biofilm producer $(\mathrm{ODc}<\mathrm{OD} \leq 2 \times \mathrm{ODc})[14]$.

\section{Minimum Inhibitory Concentration (MIC) of Chitosan}

Chitosan (low molecular weight) was purchased from Merck (Germany) and Stock solutions were prepared in injectable distilled water. The MIC values of chitosan against $A$. baumannii strains were determined by the Mueller-Hinton broth microdilution method [15].

\section{Photodynamic Inactivation of A. baumannii Planktonic Cells}

For this purpose, $300 \mu \mathrm{l}$ of bacterial suspensions $\left(1-2 \times 10^{8} \mathrm{CFU} / \mathrm{ml}\right)$ was placed in a 96-well microplate and then incubated with EB (final concentration of $50 \mu \mathrm{M}$ ) + acetic acid (AA) $(0.01 \%)$ in the dark and at room temperature for $15 \mathrm{~min}$. Treated cells were exposed to diode laser with power of $45 \mathrm{mw}$ for $15 \mathrm{~min}\left(40 \mathrm{~J} / \mathrm{cm}^{2}\right)$. Then, $100 \mu \mathrm{l}$ of each cell suspension, in tenfold serial dilution, was spread on nutrient agar plates. After incubation for $24 \mathrm{~h}$ at $37^{\circ} \mathrm{C}$, colonies were counted. All experiments were repeated three times in triplicate. Controls included bacterial suspensions incubated with $0.9 \%$ sterile saline in the dark (untreated), bacterial suspensions incubated with $\mathrm{EB}(50 \mu \mathrm{M})$ alone or AA alone and $\mathrm{EB}(50 \mu \mathrm{M})+\mathrm{AA}(0.01 \%)$ in the dark [16].

\section{Photodynamic Inactivation of A. baumannii Biofilms}

The overnight culture of strains was diluted (1:100) into fresh TSB (supplemented with $0.2 \%$ glucose). Then, the diluted culture was transferred into 96-well polystyrene microplates (SPL, Korea) and incubated for $24 \mathrm{~h}$ at $37^{\circ} \mathrm{C}$. After biofilm formation, the medium of each well was aspirated and wells were washed twice with $0.9 \%$ sterile saline to remove the planktonic cells. In the next step, 24 h-old biofilms were treated with EB (at the final concentration of $100 \mu \mathrm{M})+\mathrm{AA}(0.01 \%)$ or $\mathrm{EB}$ (at the final concentration of $100 \mu \mathrm{M})+\mathrm{AA}(0.01 \%)+$ chitosan (1/2 MIC) for $15 \mathrm{~min}$ and subsequently irradiated with laser light for $30 \mathrm{~min}\left(80 \mathrm{~J} / \mathrm{cm}^{2}\right)$. Controls included 
biofilms incubated with $0.9 \%$ sterile saline (untreated), EB $(100 \mu \mathrm{M})+\mathrm{AA}(0.01 \%)$, AA $(0.01 \%)$ alone or EB $(100 \mu \mathrm{M})+\mathrm{AA}(0.01 \%)+$ chitosan $(1 / 2 \mathrm{MIC})$ in the dark. Adherent cells in biofilms were removed from the microwells by scraping and by vigorous pipetting. Finally, the cells were serially diluted and plated on the nutrient agar for the determination of CFU/ml [13].

\section{Cytotoxicity and Phototoxicity Assay}

The standard colorimetric 3-(4, 5-dimethylthiazol2-yl)-2, 5-diphenyl tetrazolium bromide (MTT) assay was performed to determine the biocompatibility of $\mathrm{AA}+\mathrm{EB}+$ chitosan to human fibroblast under dark and light conditions. Human fibroblast cells (provided by the Stem Cell Technology Center, Tehran, Iran) were seeded into 96-well plates in Dulbecco's Modified Eagle Medium (DMEM) containing 10\% heat-inactivated fetal bovine serum and incubated for $48-72 \mathrm{~h}$ in $5 \% \mathrm{CO}_{2}$. The cells ( $90 \%$ confluency) were treated with $\mathrm{AA}+\mathrm{EB}+$ chitosan at $37^{\circ} \mathrm{C}$ for $15 \mathrm{~min}$ in the dark. After discarding the photosensitizer solution, cells were irradiated with green light $(80 \mathrm{~J} / \mathrm{cm} 2)$. Fibroblast cells were also tested by $\mathrm{AA}+\mathrm{EB}+$ chitosan without light irradiation (dark toxicity). Then, the cells were re-supplied with growth medium and incubated overnight at $37^{\circ} \mathrm{C}$. Following incubation, the medium was removed and cells were washed with PBS. Afterwards, MTT solution at a concentration of $0.5 \mathrm{mg} / \mathrm{ml}$ was added to medium and cells were incubated for $4 \mathrm{~h}$ at $37{ }^{\circ} \mathrm{C}$. The medium was carefully removed and the crystals were dissolved by adding dimethyl sulfoxide for $15 \mathrm{~min}$. The absorbance of the formazan solution was determined by an ELISA plate reader (Hiperion, Germany) at $540 \mathrm{~nm}$. The cell viability was calculated based on control sample without any treatment as 100\%. Each experiment was performed in triplicate [17].

\section{Statistical Analysis}

All values were represented as mean \pm standard error. Statistical analysis was done by post hoc Tukey tests $(P<0.05)$ using GraphPad Prism 6.

\section{Results}

\section{Quantification of Biofilm Formation}

According to the crystal violet staining results, A. baumannii ATCC BAA 747, A. baumannii AB1, and A. baumannii $\mathrm{AB} 2$ were considered as weak, moderate, and strong biofilm producer strains, respectively.

\section{Determination of Chitosan MIC}

The MIC value of chitosan against all the tested strains was $25 \mathrm{mg} / \mathrm{ml}$.

\section{PDI against Planktonic Cells}

Photodynamic inactivation at a concentration of $50 \mu \mathrm{M} \mathrm{EB}$ (without acetic acid) was ineffective against all tested $A$. baumannii strains (in planktonic form) and only caused less than $1 \log _{10}$ CFU reduction in the number of viable bacteria. A. baumannii strains were not significantly affected by the PDI treatment even after the erythrosine concentration was raised up to $400 \mu \mathrm{M}$ (without acetic acid). PDI with EB in $0.01 \%$ acetic acid (AA) showed promising results against planktonic cells of A. baumannii. As shown in Fig. 1, AA $(0.01 \%)$ alone and in combination with $\mathrm{EB}(50 \mu \mathrm{M})$ in the dark caused less than $1 \log _{10} \mathrm{CFU}$ reduction in the number of bacterial cells in comparison with the untreated control while EB-mediated PDI under acidic condition caused a significant reduction in viable count of the tested strains (> $7 \mathrm{CFU} / \mathrm{ml})$.
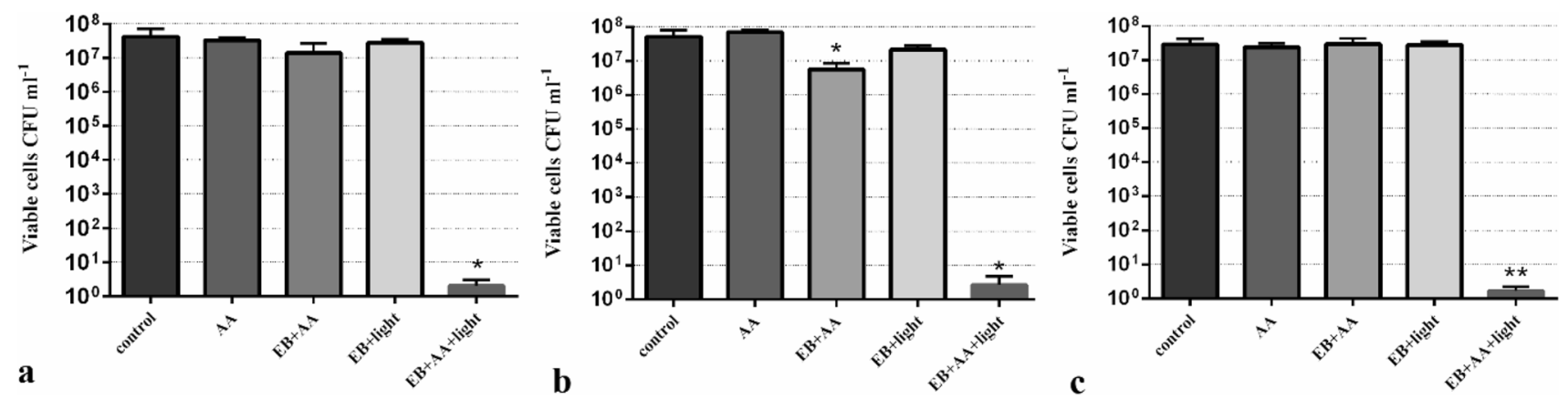

Fig. 1 Photodynamic inactivation of a A. baumannii ATCC BAA 747, b A. baumannii AB1, c A. baumannii AB2 planktonic cells. Control: untreated group, AA: acetic acid (0.01\%), EB: $50 \mu \mathrm{M}$ erythrosine B, light: $40 \mathrm{~J} / \mathrm{cm}^{2}$. * Significant at $p<0.05$, ** significant at $p<0.005$ 


\section{PDI Against Biofilms}

In this study, lethal PDI was defined as the treatment that resulted in $a \geq 3 \log _{10}$ reduction in CFU. As shown in Fig. 2, PDI mediated by $\mathrm{EB}+\mathrm{AA}$ did not cause lethal effect on biofilm-associated cells of A. baumannii ATCC BAA 747. However, the lethal effect of PDI on biofilm of this strain was observed after the addition of chitosan at sub-MIC (1/2 MIC) to EB. AA $(0.01 \%)$ alone, AA $(0.01 \%)+\mathrm{EB}(50 \mu \mathrm{M})$, and $\mathrm{AA}(0.01 \%)+\mathrm{EB}$ $(50 \mu \mathrm{M})+$ chitosan $(1 / 2 \mathrm{MIC})$ in the absent of light did not show significant effect of the viability of A. baumannii ATCC BAA 747 biofilm.

Figure 3 demonstrates that the A. baumannii AB 1 biofilm cells were more susceptible to PDI treatment in comparison to A. baumannii ATCC BAA 747. Both PDI treatments mediated by $\mathrm{EB}+\mathrm{AA}$ and $\mathrm{EB}+\mathrm{AA}$ in combination of chitosan resulted in a lethal effect on $A$. baumannii $\mathrm{AB} 1$ biofilm. The $\mathrm{AA}$ alone, $\mathrm{AA}+\mathrm{EB}$, and $\mathrm{AA}+\mathrm{EB}+$ chitosan showed dark toxicity effect on biofilm cells of $\mathrm{AB} 1$ clinical isolate.

The effect of PDI on biofilm of A. baumannii AB2 is displayed in Fig. 4. The lethal effect of PDI was achieved only by adding of chitosan to AA + EB. The AA alone, $\mathrm{AA}+\mathrm{EB}$, and $\mathrm{AA}+\mathrm{EB}+$ chitosan showed dark toxicity effect on biofilm cells of $\mathrm{AB} 2$ clinical isolate.

\section{Cytotoxicity and Phototoxicity of the Mixture of $\mathrm{EB}+\mathrm{AA}+\mathrm{Ch}$ on Human Fibroblasts}

As shown in Fig. 5, exposure of fibroblasts to green light $\left(80 \mathrm{~J} / \mathrm{cm}^{2}\right)$ in the presence of erythrosine $\mathrm{B}$, acetic acid, and chitosan $(\mathrm{EB}+\mathrm{AA}+\mathrm{Ch})$ did not induce significant cytotoxicity $(p>0.05)$; also, incubation of fibroblasts with $\mathrm{EB}+\mathrm{AA}+\mathrm{Ch}$ without illumination did not significantly influence viability of fibroblast cells.

\section{Discussion}

A. baumannii causes diverse nosocomial infections and its increased antibiotic resistance aroused the interest of biomedical researchers. The virulence factors including the ability to form biofilm and survive in harsh environmental conditions have created challenges in the management of critically ill patients in hospital intensive care units (ICUs) [18].

The optimal treatment for multidrug-resistant A. baumannii hospital-acquired infections has not been established. So, there is a serious demand for new therapeutic approaches for efficient treatment of planktonic as well as biofilm cells. PDI targets a broad-spectrum of microorganisms, independently of their antimicrobial resistance profiles and the effect of photodynamic inactivation (PDI) on A. baumannii has been reported previously [19-21]. To the best of our knowledge,
Fig. 2 Photodynamic inactivation of A. baumannii ATCC BAA 747 biofilm. Control: untreated group, AA: acetic acid (0.01\%), EB: $100 \mu \mathrm{M}$ erythrosine, Ch: chitosan (1/2 MIC), light: $80 \mathrm{~J} / \mathrm{cm}^{2}$. **Significant at $p<0.005$

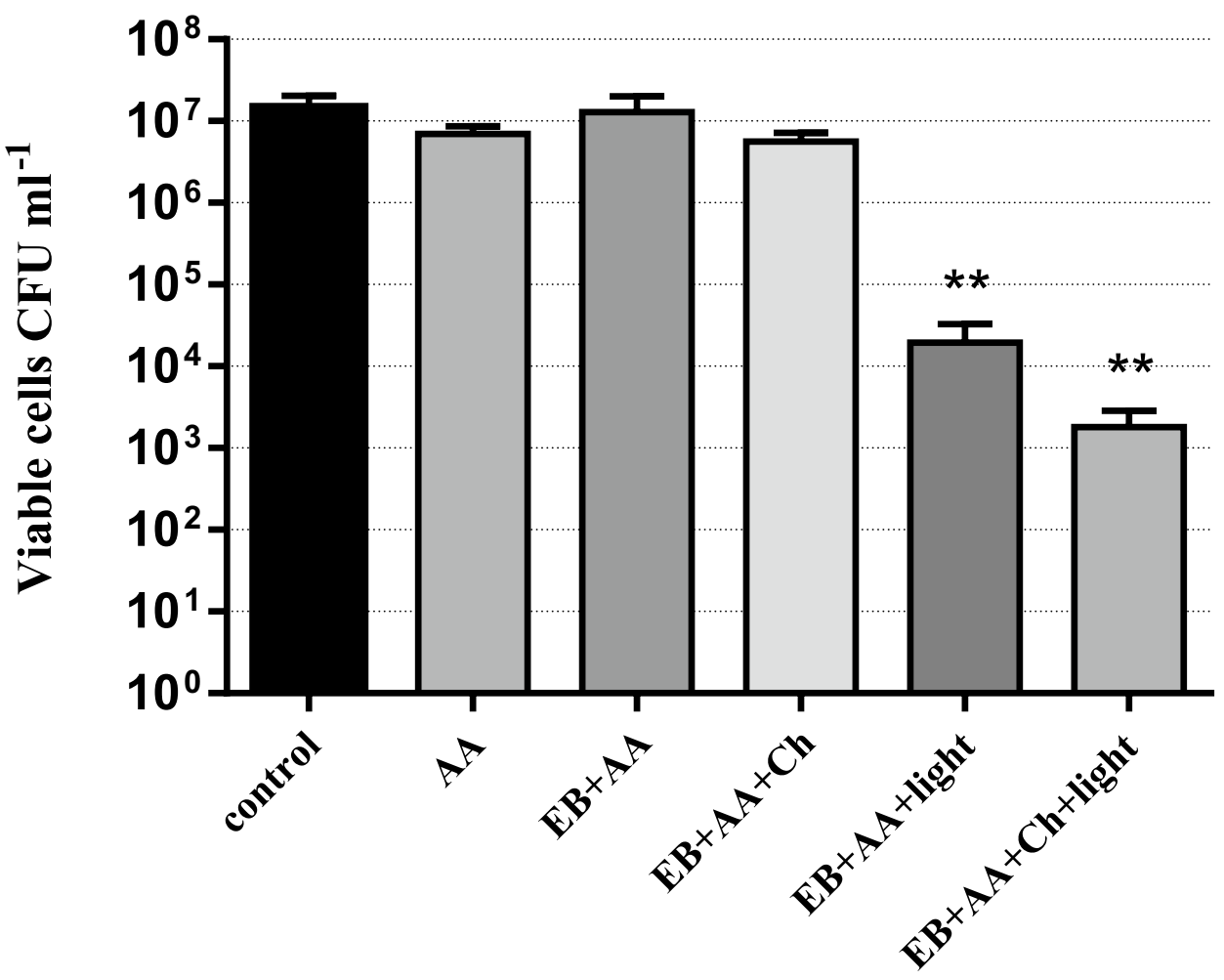


Fig. 3 Photodynamic inactivation of $A$. baumannii $\mathrm{AB} 1$ biofilm. Control: untreated group, AA: acetic acid (0.01\%), EB: $100 \mu \mathrm{M}$ erythrosine, Ch: chitosan (1/2 MIC), light: $80 \mathrm{~J} /$ $\mathrm{cm}^{2}$. $* *$ Significant at $p<0.005$
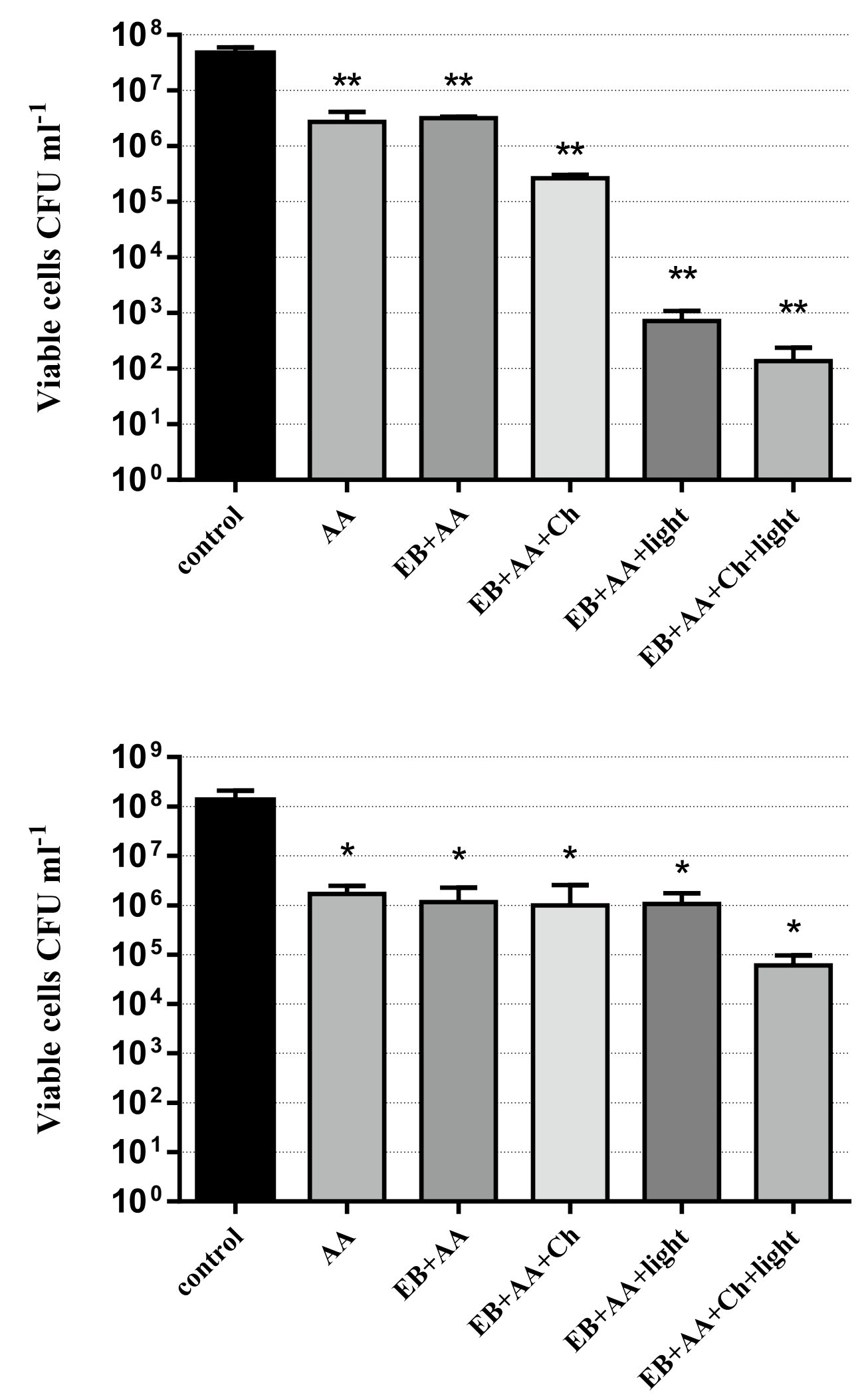

Fig. 4 Photodynamic inactivation of A. baumannii $\mathrm{AB} 2$ biofilm. Control: untreated group, AA: acetic acid $(0.01 \%)$, EB: $100 \mu \mathrm{M}$ erythrosine, $\mathrm{Ch}$ : chitosan (1/2 MIC), light: $80 \mathrm{~J} /$ $\mathrm{cm}^{2}$. ** Significant at $p<0.005$
EB-mediated PDI has not been employed against $A$. baumannii. In this study, antibacterial effects of EB-mediated PDI against $A$. baumannii planktonic and biofilm cells were evaluated. PDI using EB (range 50-400 $\mu \mathrm{M}$ ) did not cause any reduction in the numbers of $\mathrm{CFU} / \mathrm{ml}$ of planktonic cells in comparison to the control group. Gram-positive bacteria 
Fig. 5 Cell viability of human fibroblasts following treatment with $\mathrm{EB}+\mathrm{AA}+\mathrm{Ch}$ in the presence and absence of light. Control: untreated group, AA: acetic acid $(0.01 \%)$, EB: $100 \mu \mathrm{M}$ erythrosine, Ch: chitosan ( $1 / 2$ MIC), light: $80 \mathrm{~J} / \mathrm{cm}^{2}$

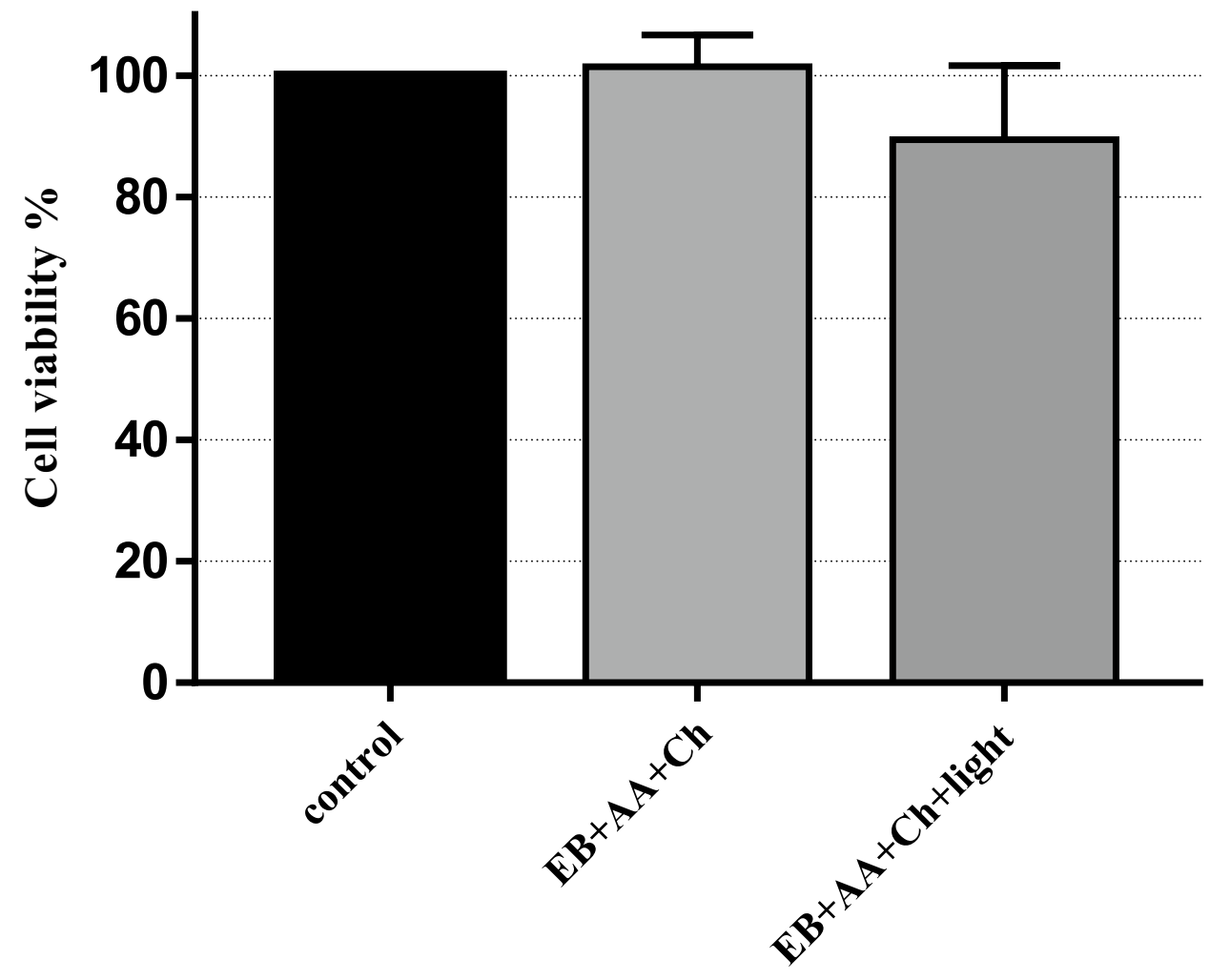

are susceptible to EB-mediated PDI [22, 23], while gramnegative bacteria, such as $A$. baumannii, are less susceptible [24] or resistant to EB-mediated PDI [25, 26]. Gram-positive bacteria have a permeable cell wall that does not restrict the penetration of PSs. In contrast, the cell envelope of gramnegative bacteria consists of an outer membrane which makes a barrier (physical and functional) between the cell and its environment and thus many of the commonly used PS in PDI could not penetrate this gram-negative barrier. Furthermore, the outer membrane of gram-negative bacteria is impermeable to anionic compounds due to its negative surface charge [27].

PSs bearing an anionic charge such as EB need agents that increase their penetration into the outer membrane of gram-negative bacteria. So we examine the effect of acetic acid $(0.01 \%)$ on the erythrosine-mediated PDI of $A$. baumannii. The results showed the addition of acetic acid $(0.01 \%)$ to EB, potentiated the PDI against $A$. baumannii cells. The planktonic cells of $A$. baumannii were almost eradicated by illumination in the presence of EB and AA. The mechanisms behind the additive effect of acetic acid on EB-mediated PDI are unknown. It seems that the low $\mathrm{pH}(\mathrm{pH}<3.5)$ associated with the presence of acetic acid can cause the formation of erythrosine monoanionic form that would be potentially more effective than dianionic form in the PDI efficacy of gram-negative bacteria [28]. In fact, the monoanionic form of erythrosine possesses a higher binding affinity to the bacterial outer membrane than dianionic form.
The augmentation effect of acetic acid on EB-mediated PDI was not enough to cause lethal effect on A. baumannii biofilm cells. Microcolonies as the basic structural unit of biofilms are usually composed of 10-25\% cells and 75-90\% extracellular polymeric substances (EPS); EPS can serve as a mechanical barrier for the penetration of the photosensitizer and the diffusion of light [29, 30]. Thus, agents that affect the biofilm's structural organization would allow better penetration of both photosensitizer and light into the biofilm structure and result in a greater photodynamic efficacy. In this study, chitosan enhanced the anti-biofilm efficacy of erythrosine B-mediated PDI against $A$. baumannii. Enhancement of the efficacy of EB-mediated PDI using chitosan might be attributed to the following three reasons: (1) the ability of chitosan to disrupt the biofilm structure and thus helping the PDI to act on the cells that are released from the biofilm, (2) the ability of chitosan to permeabilize the outer membrane of gram-negative bacteria such as A. baumannii, and (3) the ability of cationic chitosan to act as a drug carrier for delivery of erythrosine to biofilm [12, 31, 32].

For clinical use, an ideal PDI should produce little effect on mammalian tissues in the area of infection. So, the cytotoxicity and phototoxicity of the mixture of chitosan + acetic acid + erythrosine were assessed on human fibroblast cells that are involved in wound healing process. The mixture of $\mathrm{EB}+\mathrm{AA}+\mathrm{Ch}$ with and without illumination did not significantly influence on cell viability and thus this mixture has the potential for clinical use in antimicrobial treatment. 


\section{Conclusions}

PDI mediated by erythrosine + acetic acid can cause a lethal effect on A. baumannii in plankotonic form while the lethal effect of PDI on A. baumannii (ATCC BAA 747 and AB2) biofilm can be achieved only by adding chitosan to $\mathrm{EB}$ in the presence of acetic acid. Our results also provide evidence that fibroblast cells can survive under PDI conditions (used in this study) that are lethal to A. baumannii cells. In summary, PDI mediated by the mixture of erythrosine, acetic acid, and chitosan can be considered as a new therapeutic option for biofilm-related wound infections caused by multidrug-resistant $A$. baumannii.

Acknowledgements The authors wish to thank vice chancellor of research of Shahid Chamran University of Ahvaz for providing research grant (Grant No. SCU.SB98.37181). The authors also acknowledge the support of Iran's National Elite Foundation (INEF).

\section{Compliance with Ethical Standards}

Conflict of interest The authors declare that they have no conflicts of interest.

\section{References}

1. Antunes L, Visca P, Towner KJ (2014) Acinetobacter baumannii: evolution of a global pathogen. Pathog Dis 71:292-301

2. Lee C-R, Lee JH, Park M, Park KS, Bae IK, Kim YB et al (2017) Biology of Acinetobacter baumannii: pathogenesis, antibiotic resistance mechanisms, and prospective treatment options. Front Cell Infect Microbiol 7:55

3. Harding CM, Hennon SW, Feldman MF (2018) Uncovering the mechanisms of Acinetobacter baumannii virulence. Nat Rev Microbiol 16:91

4. Hamblin MR (2016) Antimicrobial photodynamic inactivation: a bright new technique to kill resistant microbes. Curr Opin Microbiol 33:67-73

5. Kashef N, Hamblin MR (2017) Can microbial cells develop resistance to oxidative stress in antimicrobial photodynamic inactivation? Drug Resist Updat 31:31-42

6. Wood S, Metcalf D, Devine D, Robinson C (2006) Erythrosine is a potential photosensitizer for the photodynamic therapy of oral plaque biofilms. J Antimicrob Chemother 57:680-684

7. Guo Y, Rogelj S, Zhang P (2010) Rose Bengal-decorated silica nanoparticles as photosensitizers for inactivation of gram-positive bacteria. Nanotechnology 21:065102

8. Demidova TN, Hamblin MR (2005) Effect of cell-photosensitizer binding and cell density on microbial photoinactivation. Antimicrob Agents Chemother 49:2329-2335

9. De Melo WC, Avci P, De Oliveira MN, Gupta A, Vecchio D, Sadasivam M et al (2013) Photodynamic inactivation of biofilm: taking a lightly colored approach to stubborn infection. Exp Rev Anti Infect Ther 11:669-693

10. Kardumyan VV, Aksenova NA, Glagolev NN, Timashev PS, Solovieva AB (2020) Influence of acetic acid on the photocatalytic activity of photosensitiser-amphiphilic polymer complexes in the oxidation reaction of tryptophan. J Chem Phys 152:194901
11. Frade ML, De Annunzio SR, Calixto GMF, Victorelli FD, Chorilli M, Fontana CR (2018) Assessment of chitosan-based hydrogel and photodynamic inactivation against Propionibacterium acnes. Molecules 23:473

12. Li S, Wang Y, Li X, Lee BS, Jung S, Lee MS (2019) Enhancing the thermo-stability and anti-biofilm activity of alginate lyase by immobilization on low molecular weight chitosan nanoparticles. Int J Mol Sci 20:4565

13. Darabpour E, Kashef N, Mashayekhan S (2016) Chitosan nanoparticles enhance the efficiency of methylene blue-mediated antimicrobial photodynamic inactivation of bacterial biofilms: An in vitro study. Photodiagnosis Photodyn Ther 14:211-217

14. Liu H, Zhao Y, Zhao D, Gong T, Wu Y, Han H et al (2015) Antibacterial and anti-biofilm activities of thiazolidione derivatives against clinical staphylococcus strains. Emerg Microbes Infect $4: 1-6$

15. Clinical and Laboratory Standards Institute (2006) Performance Standards for Antimicrobial Susceptibility Testing: Sixteenth Informational Supplement M100-S16. CLSI, Wayne, PA, USA

16. Fekrirad Z, Kashef N, Arefian E (2019) Photodynamic inactivation diminishes quorum sensing-mediated virulence factor production and biofilm formation of Serratia marcescens. World J Microbiol Biotechnol 35:191

17. Darabpour E, Kashef N, Amini SM, Kharrazi S, Djavid GE (2017) Fast and effective photodynamic inactivation of 4-dayold biofilm of methicillin-resistant Staphylococcus aureus using methylene blue-conjugated gold nanoparticles. J Drug Deliv Sci Technol 37:134-140

18. Garnacho-Montero J, Timsit JF (2019) Managing Acinetobacter baumannii infections. Curr Opin Infect Dis 32:69-76

19. Wang Y, Harrington OD, Wang Y, Murray CK, Hamblin MR, Dai T (2017) In vivo investigation of antimicrobial blue light therapy for multidrug-resistant Acinetobacter baumannii burn infections using bioluminescence imaging. J Vis Exp 28:54997

20. Li J, Qin M, Liu C, Ma W, Zeng X, Ji Y (2020) Antimicrobial photodynamic therapy against multidrug-resistant Acinetobacter baumannii clinical isolates mediated by aloe-emodin: An in vitro study. Photodiagnosis Photodyn Ther 29:101632

21. De Mello MM, De Barros PP, De Cassia BR, Alves SR, Ramanzini NP, Figueiredo-Godoi LMA et al (2019) Antimicrobial photodynamic therapy against clinical isolates of carbapenemsusceptible and carbapenem-resistant Acinetobacter baumannii. Lasers Med Sci 34:1755-1761

22. Borba ASM, da Silva Pereira SM, Borba MCM, Paschoal MAB, de Jesus Tavarez RR, de Castro RC et al (2017) Photodynamic therapy with high-power LED mediated by erythrosine eliminates Enterococcus faecalis in planktonic forms. Photodiagnosis Photodyn Ther 19:348-351

23. Tokubo LM, Rosalen PL, Sardi J.d C.O., Freires IA, Fujimaki M, Umeda JE, et al (2018) Antimicrobial effect of photodynamic therapy using erythrosine/methylene blue combination on Streptococcus mutans biofilm. Photodiagnosis Photodyn Ther 23:94-98

24. Yassunaka NN, de Freitas CF, Rabello BR, Santos PR, Caetano $\mathrm{W}$, Hioka N et al (2015) Photodynamic inactivation mediated by erythrosine and its derivatives on foodborne pathogens and spoilage bacteria. Curr Microbiol 71:243-251

25. En-Sheng K, Nazzal S, Tseng YH, Chen CP, Tsai T (2012) Erythrosine-Mediated Photodynamic Inactivation of Bacteria and Yeast Using Green Light-Emitting Diode Light. J Food Drug Anal 20:951-956

26. Rossoni RD, Junqueira JC, Santos ELS, Costa ACB, Jorge AOC (2010) Comparison of the efficacy of Rose Bengal and erythrosin in photodynamic therapy against Enterobacteriaceae. Lasers Med Sci 25:581-586 
27. Hamblin MR, Hasan T (2004) Photodynamic therapy: a new antimicrobial approach to infectious disease? Photochem Photobiol Sci 3:436-450

28. Montero E, García M, Broncano Villegas MÁ, Llopis J (2008) Spectral $\mathrm{pH}$ dependence of erythrosin $\mathrm{B}$ in sol-gel silica coatings and buffered solutions. Bol Soc Esp Ceram 47:1-6

29. Tenke P, Kovacs B, Jäckel M, Nagy E (2006) The role of biofilm infection in urology. World J Urol 24:13-20

30. Wu M, Xu L, Cai Z, Huang S, Li Y, Lei L, Huang X (2020) Disinfection of Cariogenic Pathogens in Planktonic Lifestyle, Biofilm and carious dentine with antimicrobial photodynamic therapy. Photochem Photobiol 96:170-177

31. Li XF, Feng XQ, Yang S, Fu GQ, Wang TP, Su ZX (2010) Chitosan kills Escherichia coli through damage to be of cell membrane mechanism. Carbohydr Polym 79:493-499
32. Maldonado-Carmona N, Ouk TS, Calvete MJ, Pereira MM, Villandier N, Leroy-Lhez S (2020) Conjugating biomaterials with photosensitizers: advances and perspectives for photodynamic antimicrobial chemotherapy. Photochem Photobiol Sci $19: 445-461$

Publisher's Note Springer Nature remains neutral with regard to jurisdictional claims in published maps and institutional affiliations. 